\title{
Predicting Stock Prices Using Machine Learning Methods and Deep Learning Algorithms: The Sample of the Istanbul Stock Exchange
}

\author{
Ugur DEMIREL ${ }^{(1)}$, Handan CAM ${ }^{(1)}$, Ramazan UNLU* \\ Faculty of Economics and Administrative Sciences, Gumushane University, Gumushane, 29000, Turkey
}

\section{Highlights}

- The paper focusesed on Istanbul Stock Exchange (ISE) prediction

- MLP, SVM and LSTM models were compared with their forecasting performances

- MLP and LSTM models outperformed SVM model in estimating the stock prices

\section{Article Info}

Received: $23 / 01 / 2020$

Accepted: 01/07/2020

\begin{abstract}
Stock market prediction in financial and commodity markets is a major challenge for speculators, investors, and companies but also profitable with an accurate prediction. Thus, obtaining accurate prediction results becomes extremely important especially while the stock market is essentially volatile, nonlinear, complicated, adaptive, nonparametric and unpredictable in nature. This study aims to forecast the opening and closing stock prices of 42 firms listed in Istanbul Stock Exchange National 100 Index (ISE-100) using well-known machine learning methods, Multilayer Perceptrons (MLP) and Support Vector Machines (SVM) models and deep learning algorithm, Long Short Term Memory (LSTM) by comparing their forecasting performances. The analysis includes 9 years of data from 01.01.2010 to 01.01.2019. For each firm 2249 data for the opening and 2249 for the closing stock prices were established as daily data sets. Forecasting performance of these methods was evaluated by applying different criteria for each model: root mean squared error (RMSE), mean squared error (MSE) and R-squared (R2). The results of this study show that MLP and LSTM models become advantageous in estimating the opening and closing stock prices comparing to SVM model.
\end{abstract}

\section{INTRODUCTION}

Stock market prediction in financial and commodity markets is a major challenge facing speculators, investors, and companies assuming that future events are at least partly dependent on current and past events and data in their search for market forecasting. However, financial time series are among the noisiest and most difficult signals to predict since the stock market is essentially volatile, nonlinear, complicated, adaptive, nonparametric and unpredictable in nature [1-3]. In finance, many macro-economic issues such as firm policies, political events, general economic circumstances and expectations of traders affect the stock market's movements [3-5]. It is therefore quite difficult to predict changes in financial market prices. According to academic research, market price movements are not random. Instead, they act in a highly nonlinear, dynamic way [2], [6]. However, in recent years, the development of computer hardware and software technologies has made it possible to support computation in finance. Thanks to its potential to generate great profits and capital, this use of artificial intelligence resources in the finance industry is of great interest. Therefore, an emerging discipline, computational finance which is the integration of economics, mathematics, and large-scale computation has gained considerable interest and motivated further researches in multi-disciplines [4-5]. 
Machine learning methods widely used in the stock forecasting model are support vector machines (SVM), neural networks $(\mathrm{NN})$, models combining them with other algorithms and Long Short-term Memory (LSTM) as a deep learning method. There have been a number of studies using artificial neural networks (ANNs) in time-series modeling and forecasting [7] and ANN models have been used successfully in forecasting studies across a wide range of disciplines. We will begin by presenting the most well-known and widely-used network, multi-layer feedforward networks, which is a particular structure of ANNs applied in a variety of applications including forecasting. One of the first successful applications of multilayer perceptron (MLP) was reported by [8] and following years many other problems have been solved by MLP including student grade point averages [9], ozone level [10], commodity prices [11], advertising [12], electric load consumption [13], forecasting macroeconomic data [14], railway traffic forecasting [15] and financial time series forecasting [16]. Forecasting financial markets such as the stock markets have been researched at length in [17]'s study. The same year, the Standard \& Poors 500 Index has been modeled by [18] using different neural network architectures that can be trained to perform, yet the probabilistic neural network performs slightly better than the multilayer perceptron. Mostafa [19] used multi-layer perceptron (MLP) and generalized regression neural networks in order to forecast the Kuwait Stock Exchange (KSE) closing price changes using data for the period 2001-2003 which has concluded that neural networks are performing well in predicting stock exchange movements in developing markets. In their papers, Naeini et al. [20] have used two forms of neural networks, a feedforward Multilayer Perceptron (MLP) and an Elman recurrent network to estimate a company's stock value based on its market-value background. The experimental results show that the MLP neural network outperforms Elman recurrent network and linear regression method. Despite the volatility in the markets, multilayer networks with dynamic backpropagation have been used successfully by [21] to predict the stock price of Bombay Stock Exchange (BSE). In Turkey, Kutlu et al. [22] have used Multi-Layer Perceptron and Generalized Feed Forward networks which have better performances than moving averages to predict the Istanbul Stock Exchange (ISE) market index value including the data gathered for the period of July 1, 2001, through February 28, 2003, from the Central Bank of the Republic of Turkey. Yumlu et al. [23] have made a comparison of the multilayer perceptron (MLP), recurrent neural network (RNN) and the mixture of experts (MoE) structure including 12 years data of Istanbul stock exchange (ISE) index (XU100) between the years of 1990 to 2002. Each model has been compared with well-known market-return index criterions including correlation $(\xi)$, mean absolute error (MAE), mean squared error (MSE), hit rate $\left(H_{R}\right)$, positive hit rate $\left(H_{R}^{+}\right)$ and negative hit rate $\left(H_{R}^{-}\right)$. Finally, it has been observed that the MoE neural structure is superior over other models. Guresen et al. [24] have assessed the feasibility of neural network models in stock-market predictions including the analyses of dynamic artificial neural network (DAN2), multi-layer perceptron (MLP), and the hybrid neural networks using generalized autoregressive conditional heteroscedasticity (GARCH) to extract new input variables. Each model is compared by Mean Absolute Deviate (MAD) and Mean Square Error (MSE) using actual exchange rate values of the NASDAQ Stock Exchange index on a daily basis.

Although the neural network has been widely used in the field of financial time series forecasting owing to its outstanding learning ability and broad applicability to a variety of business problems, recently the support vector machines (SVM), has been conducted successfully in the prediction of the stock price index movements. [25-28] have demonstrated that support vector machines (SVM), a novel neural network algorithm developed by Vapnik and his colleagues [29], has performed well in classification tasks, regression and time series prediction, respectively. Cao and Tay [30], Tay and Cao [31] recently have questioned whether the SVM is feasible to predict financial time series by comparing it with a multi-layer back-propagation (BP) neural network. For data sets, they used five real futures obtained from the Chicago Mercantile Market and several foreign bond indices. The experiment result shows that SVMs outperform the multi-layer back-propagation (BP) networks where mean absolute error, normalized mean square error, directional symmetry, and weighted directional symmetry has been conducted. By integrating SVR and self-organizing map (SOM), Tay and Cao [32] have introduced a two-stage architecture in order to properly identify the dynamic input-output relationships implicit in the financial data. The parameters such as $\mathrm{C}$ and 
$\varepsilon$ used for the kernel functions are basically determined experimentally and it is shown that the overall approach has better prediction performance and higher convergence rate as in contrast to a single SVR approach. Tay and Cao [33] have suggested a modern version of SVR called $C$-ascending SVMs for the prediction of financial series as similar to the discounted least-squares approach whereby the most recent $\varepsilon$-insensitive errors are weighted and the more distant ones are deweighted. A variety of share indexes, including the S\&P 500, have been evaluated for both exponential and linear weight functions and it has been concluded that, compared to a standard SVR method, this approach can present better performance. For the purpose of predicting the direction of the change in daily stock price in the Korea composite stock price index (KOS-PI), Kim [34] has used SVM with 12 technical indicators including A/D oscillator, CCI, disparity5, disparity10, momentum, stochastic K\%, stochastic D\%, stochastic slow D\%, Williams' \%R, OSCP, ROC and RSI which are used to make up the initial attributes. Analysis of the experimental results has proved that applying SVM in financial prediction by comparing it with a back-propagation neural network (BPN) and case-based reasoning (CBR) is feasible and it is advantageous. Pai and Lin [35], have developed a prediction model integrating ARIMA and SVM models in order to estimate the daily closing prices of ten companies. The hybrid model integrated ARIMA and SVM has been observed to significantly reduce all estimation errors when compared to models using only ARIMA and SVM only. In their study, Huang et al. [2] have investigated weekly movement direction of NIKKEI 225 with SVM by evaluating its performance with those of Elman backpropagation neural networks, linear discriminant analysis, and quadratic discriminant analysis. The findings of the experiment indicate that SVM exhibits better forecasting performance than the other classification methods. Kumar and Thenmozhi [36] in their study have presented SVM and random forest to forecast the direction of the change in the daily stock price in the S\&P CNX NIFTY Market Index of the National Stock Exchange by comparing the results with those of the artificial neural network, logit models and discriminant analysis. Their results demonstrated that SVM outperformed the other methods like the random forest, neural networks, and other traditional models. Following year, Kumar and Thenmozhi [37] have examined the feasibility of ANN, ARIMA, SVM, and random forest regression models in forecasting the S\&P CNX NIFTY Index return by measuring their performance statistically and financially through a trading experiment which propose that the SVM model demonstrates better performance than other models used in their research. Hsu et al. [38] have developed two-stage architecture by using the self-organizing map and support vector regression with an examination of seven major stock markets to forecast stock prices. The results suggest that the two-stage architecture offers a viable solution for forecasting stock prices. In their studies, Kara et al. [3] have compared the performance of ANN and SVM for the purpose of estimating the ISE-100 Index. For the analysis, the data set covering the closing prices in the period from 2 January 1997-31 December 2007 has been used with selected 10 technical indicators including A/D oscillator, CCI, MACD, momentum, RSI, stochastic K\%, stochastic D\%, simple moving average (SMA), weighted moving average (WMA) and Williams' \%R. Although the results are successful in both methods, it is found that ANN has 75.74\% and SVM had 71.52\% predictive performance. In another study published at the same year, Ozdemir et al. [39] have estimated the movement direction of the ISE-100 Index return by using both Logistic Regression (LR) and Support Vector Machines (SVM) on monthly data covering the period of February 1997 - December 2010. A total of 167 data sets are divided into 138 data training sets in which the models were installed and 29 data sets of predictions of the validity of the models. According to the results of the study, support vector machines can be used effectively by investors and researchers to predict the stock returns as an alternative method. Tayyar and Tekin [40] have used Support Vector Machines (SVM) to forecast the movement direction of the Istanbul Stock Exchange National 100 Index (ISE-100). They compared the classification performance of SVM with Logistic Regression (LR) method used in this study in order to predict the movement direction of the ISE-100 Index. The analysis includes data sets of 4226 data that have been established daily, weekly and monthly from 03.04.1995 to 19.03.2013. They have built 4 models for each dataset and evaluated index movement direction forecasting performance of these methods by applying different criteria for each model. They observed that the best estimation of the movement direction of ISE-100 Index was in Model 1 (70.0\%) among other models with an increase of $(82.89 \%)$ and a decrease of $(54.68 \%)$ direction. Yakut et al. [41] have attempted to estimate BIST index value by using feed-forward artificial neural networks and support 
vector machines methods. They have used the variables such as exchange rates and other countries' exchanges obtained from including America exchange rate of the dollar, overnight websites between 20052012 besides three days' values of the BIST index. According to the result, artificial neural networks and support vector machines methods can be used successfully to predict the stock market index.

In recent years, long-short-term memory (LSTM) networks for recurrent networks have been introduced by [42] and have become the cutting-edge models for a variety of machine learning problems. LSTM networks, one of the most powerful deep learning models, have demonstrated great performance in pattern learning tasks, such as speech recognition, human behavior recognition, and handwriting recognition or time series prediction [43-48]. Beside the tasks mentioned above, LSTM networks have been used in many different subjects such as producing musical compositions [49], detecting protein homology without alignment [50], designing a learning system to tie knots in heart surgery [51] and learning nonregular languages [52]. However, having surveyed the literature, it is seen that there have not been many attempts to deploy LSTM in financial market prediction tasks. Giles et al. [53] applied the RNN model to the daily foreign exchange rates forecasting, and gained success in prediction in thorough experiments predicting the direction of change correctly for the next day with an error rate of $47.1 \%$. Through integrating Google's domestic patterns as public mood measures and macroeconomic factors, Xiong et al. [54] have utilized a Long Short-Term Memory neural network to model S\&P 500 volatility, with a $24.2 \%$ of mean absolute percentage error, outperforming linear Ridge/Lasso and $31 \%$ by at least autoregressive GARCH benchmarks. Roondiwala et al. [55] have presented a recurrent neural network (RNN) and Long ShortTerm Memory (LSTM) approach to estimate stock market indices. Shen et al. [56] used Bayesian-optimized recurrent neural network-LSTM to estimate the value of the coin, achieving 52\% precision. Pang et al. [57] have proposed the deep long-short-term memory neural network (LSMN) with an embedded layer vectorizing the data to forecast the stock market. The results of the experiment indicate that the LSMN model with the embedded layer is state-of-the-art with an accuracy of $57.2 \%$ for the Shanghai A-shares composite and 52.4\% for an individual stock. Fischer and Krauss [58] have deployed LSTM networks to forecast out-of-sample directional movements for the stakeholders' stocks in the S\&P 500 from 1992 until 2015 and they find that LSTM networks outperform memory-free classification approaches with $0.46 \%$ of daily returns and a $5.8 \%$ of Sharpe Ratio prior to transaction costs.

Machine learning techniques are seen to be used increasingly in financial time series forecasting as an alternative to statistical methods due to their outstanding learning and generalization ability. The main objective of this paper is to predict stock prices in the daily Borsa Istanbul National 100 Index (BIST100) using multilayer perceptron neural networks (MLP), support vector machines (SVM) and long short term memory (LSTM) models. Thus, we collected 9 years of historical data of BIST 100 between 01.01.2010 01.01.2019 and used it for the training and validation purposes. From this literature survey, we find that no previous studies have attempted to predict the stock market prices of BIST 100 through all these three above mentioned models. In this study, we aim to fill this research gap by comparing these three models to forecast the stock market prices. The remainder of this paper is organized into 4 sections. Section 2 describes the methodology. Section 3 provides the computational results and finally, section 4 contains the concluding remarks and future research directions.

\section{MATERIAL METHOD}

In our study, we have collected stock price datasets obtained from BIST (Borsa İstanbul) website https://www.borsaistanbul.com/ana-sayfa for 42 different companies listed in Istanbul Stock Exchange. Each company has daily opening and closing prices which start from 2010 to 2019 for each company. 
Figure 1 illustrates Türkiye İş Bankası A.Ş. closing stock price change over the years.

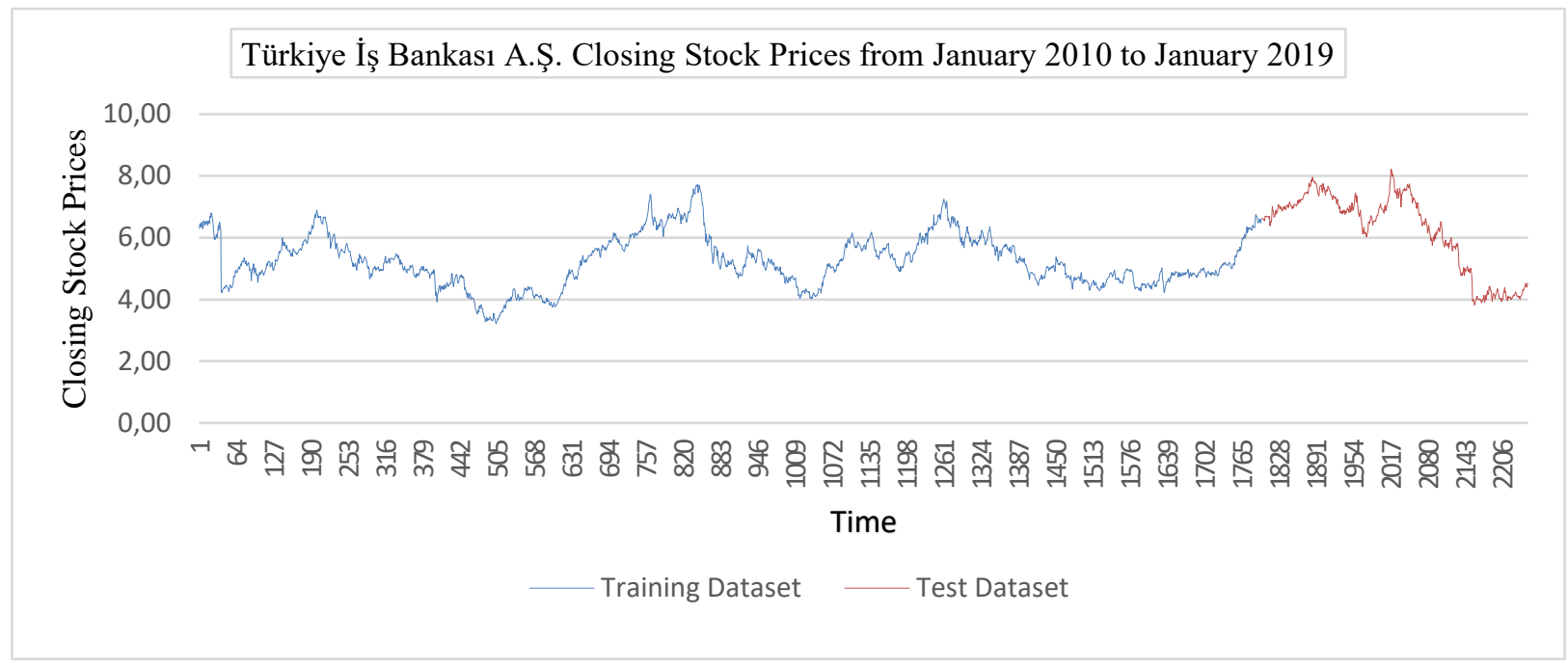

Figure 1. Türkiye Işs Bankası A.Ş. closing stock prices from 2010 to 2019 (2249 days between these dates)

For the sake of comparison of traditional machine learning algorithms and deep learning models, we chose three different algorithms called Multilayer Perceptrons, Support Vector Machines, Long Short-term Memory (LSTM) which have different mathematical foundations.

Before implementing any machine learning model to a time series dataset, we made some pre-processing as listed below.

- If there is a particular trend, make dataset stationary by subtracting data at the time of $\mathrm{t}-1$ from the data at the time of $\mathrm{t}$.

- Create some lags to make data ready for the time series analysis. We have created lags from 2 to 20 and find the optimum number of lags for each company.

- After implementing the chosen methodologies, reverse data to the original scale.

Each dataset is split as being \%80 training and \%20 test set and evaluation of the prediction models are made based on the performance on test data. In order to do that, we have used some evaluation metrics given in Table 1.

Table 1. Evaluation Metrics

\begin{tabular}{|l|c|}
\hline Evaluation Metrics & Formulation \\
\hline RMSE & $\sqrt{\frac{\sum_{i=1}^{n}\left(P_{i}-O_{i}\right)^{2}}{n}}$ \\
\hline MSE & $\frac{1}{n} \sum_{i=1}^{n}\left(y_{i}-\tilde{y}_{i}\right)^{2}$ \\
\hline $\mathrm{R}^{2}$ & $\left(\frac{\boldsymbol{n} \sum(\boldsymbol{y} \widetilde{\boldsymbol{y}})-\sum \boldsymbol{y} \sum \widetilde{\boldsymbol{y}}}{\sqrt{\boldsymbol{n}\left(\sum \boldsymbol{y}^{\mathbf{2}}\right)-\left(\sum \boldsymbol{y}\right)^{\mathbf{2}}}-\sqrt{\boldsymbol{n} \sum\left(\widetilde{\boldsymbol{y}}^{2}\right)-\left(\sum \widetilde{\boldsymbol{y}}\right)^{2}}}\right)^{2}$ \\
\hline
\end{tabular}

\subsection{Multilayer Perceptron Algorithm}

Artificial Neural Network -also named Multilayer perceptron (MLP)- is one of the machine learning methods to extract the hidden nonlinear relation from the data [59-61]. It consists of some layers called input, hidden, and output as shown in Figure 2. 


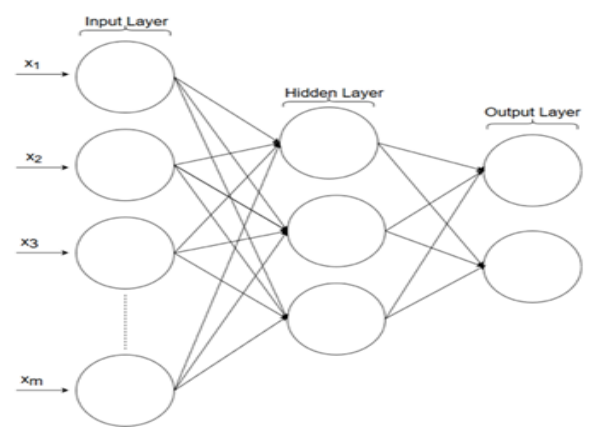

Figure 2. MLP Structure consisted of Input, Hidden, and Output layers

Data samples enter the network from input layers, and a linear combination of the values are forwarded to neurons in the next layer. This network process is called as feed-forwarded neural networks. Then the system takes the values from the output layer through the input layer to optimize weights by taking partial derivatives. This method is called backpropagation. The output of $n^{\text {th }}$ neuron in $l^{\text {th }}$ the layer is calculated based on Equation (1) as the linear combination of the previous layer such that:

$o=y_{l}^{n}=w^{T} x+b$

where $w^{T}$ is the connection weights. The value of each node is transformed by an activation function. There are some available activation functions in the literature. We have used the sigmoid one which transforms the value as being 1 or 0 based on Equation (2)

$\sigma(x)=\frac{1}{1-e^{-\left(w^{T} x+b\right)}}$.

Then, the weights should be adjusted based on Equation (3) to minimize the error for the given dataset.

$D=\left\{\left(x_{1}, t_{1}\right),\left(x_{2}, t_{2}\right), \ldots,\left(x_{d}, t_{d}\right), \ldots,\left(x_{m}, t_{m}\right)\right\}$

$E[\vec{w}]=\frac{1}{2} \sum_{d \in D}\left(t_{d}-o_{d}\right)$

In order to adjust $w_{i}$ as $w_{i}:=w_{i}+\Delta w_{i}$, following partial derivatived procedure should be utilized simultaneously for each $w_{i}$ as shown in Equation (4)

$\Delta w_{i}=-\eta \frac{\partial E}{\partial w_{i}}$

where $-\eta$ is the learning rate, $\Delta w_{i}$ is the adjustment value. After taking the derivatives, we can wrap up the adjustment rules as shown in Equation (5)

$\Delta w_{i}=-\eta \sum_{d \in D}\left(t_{d}-o_{d}\right) x_{i d}$

One needs to note that, because our problem is a regression problem, there will be a single neuron in the output layer of the MLP model.

\subsection{Support Vector Machines (SVM) Algorithm}

Support Vector Machines is one of the widely used machine learning algorithm proposed by [62]. The SVM 
is initially designed for the binary classification problem, then it is extended for the regression problem [63]. Assume we are given a dataset $\left\{\left(x_{1}, y_{2}\right), \ldots,\left(x_{l}, y_{l}\right)\right\}$, where each $x_{i} \in R$ the decision function is given by Equation (6)

$f(x)=w \phi(x)+b$.

With respect to $w_{i} \in R$ and $\} b \in R$, where $\phi$ denotes a non-linear transformation from $R^{n}$ to higherdimensional space. To make sure $f(x)$ is as flat as possible, magnitude the of the w should be minimized as in Equation (7)

$J(w)=\frac{1}{2}\|w\|$.

Subject to all residuals having a value less than $\varepsilon$; or, in Equation (8)

$w \phi\left(x_{i}\right)+b-y_{i} \leq \varepsilon$.

It is expected that it is impossible to meet this condition for any dataset. So, we can add slack variables $\xi^{+}$ and $\xi^{-}$to give some flexibility and rewrite the formulations as shown below in Equation (9)

$J(w)=\frac{1}{2}\|w\|+C \sum_{i}^{n} \xi^{+}+\xi^{-}$.

Subject to:

$y_{i}-\left(w \phi\left(x_{i}\right)+b\right) \leq \varepsilon+\xi^{+}$

$\left(w \phi\left(x_{i}\right)+b\right)-y_{i} \leq \varepsilon+\xi^{-}$

$\xi^{+} \geq 0$

$\xi^{-} \geq 0$

where $C$ is a constant value that assigns some penalty values imposed to the variables which stay outside the $\varepsilon$ margin and help to avoid being overfitting. Finally, we can calculate the loss function that ignores the error if the predicted value is less than or equal to $\varepsilon$. Thus, it can be formulated as shown in Equation (10)

$f(x)=\left\{\begin{array}{l}0, \quad \text { if } w \phi\left(x_{i}\right)+b-y_{i} \leq \varepsilon \\ \left|w \phi\left(x_{i}\right)+b-y_{i}\right|-\varepsilon, \quad \text { otherwise }\end{array}\right.$.

For the sake of mathematical convenience, the given optimization problem described above can be solved in dual form.

\subsection{Long-Short Term Memory Algorithm}

Long-Short Term Memory is developed based on a recurrent neural network proposed by [42]. As opposed to a traditional neural network, LSTM network is designed to remember what happened in the past and how this affects the current situation. To make it more concrete assume that we are given a dataset $X=$ $\left\{x^{<1>}, x^{<2>}, \ldots, x^{<t>}, \ldots, x^{<T_{x}>}\right\}$ (i.e $X$ is a sentence and $x^{<t>}$ is the $t^{t h}$ word in that sentence). A RNN network takes the information from $x^{<t>}$ and activation value $a^{<t-1>}$ from the previous time step to help prediction with $y^{<t>}$. Based on the structure of the RNN we can build the formulation of the RNN as shown in Equations (11) and (12)

$a^{<t>}=g\left(W_{a a} a^{<t-1>}+W_{a x} x^{<t>}+b_{a}\right)$ 
where $a^{<t>}$ is accounts for the activation value in time step $t, g$ is the chosen activation function, $W_{a a}$ is the parameter for the activation values, $W_{a x}$ is parameters for the input values, an $b_{a}$ is the bias value. The prediction of the corresponding sample $y^{<t>}$ can be made based on Equation (12) by using the value of $a^{<t>}$

$\hat{y}^{<t>}=g\left(W_{y a} a^{<t>}+b_{y}\right)$

where $W_{y a} a$ is the parameter matrix for the activations and $b_{y}$ is the bias value.

Optimizing the LSTM network is similar to a traditional neural network. To minimize the overall error of the system as shown in Equation (13) back-propagation algorithm can be used.

$L\left(\hat{\boldsymbol{y}}^{<t>}, \boldsymbol{h}^{<t>}\right)=\sum_{t=1}^{T_{x}}\left(\hat{\boldsymbol{y}}^{<t>}, \boldsymbol{y}^{<t>}\right)$.

In addition to RNN systems, GRU system has an additional component called memory cell based on "remembering" what happened in the past. A simple structure is shown in the following Figure 3.

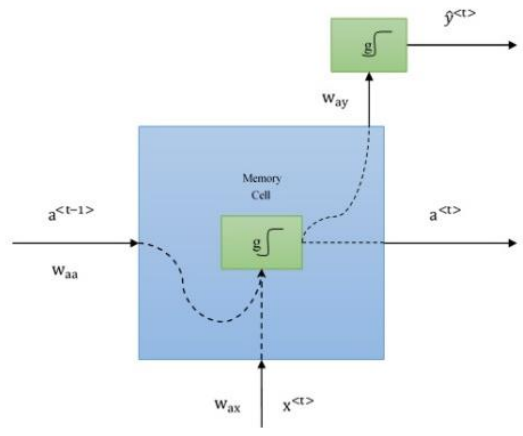

Figure 3. Simple GRU structure for sequential data

So, assume that $c^{<t>}$ used instead of $a^{<t>}$ is the memory cell works to save some important information. It needs to be decided to change the value of $c^{<t>}$ by first calculating candidate memory cell value $\hat{c}^{<t>}$ as shown in Equation (14)

$\hat{c}^{<t>}=g\left(W_{c c} c^{<t-1>}+W_{c x} x^{<t>}+b_{c}\right)$

where $g$ is the activation function, $W_{c c}$ is the parameter for the memory cell values, $W_{c x}$ is the parameter for the input data, and $c^{<t-1>}$ is the memory cell value from the previous time step. We define a parameter $\Gamma_{u}$ named as update gate which takes either 1 or 0 meaning "update" and "do not update" respectively in order to update the memory cell value in a correct time. The formulation of $\Gamma_{u}$ is as in Equation (15)

$\Gamma_{u}=g\left(W_{u c} c^{<t-1>}+W_{u x} x^{<t>}+b_{u}\right)$

where $g$ is the activation function, $W_{u c}$ and $W_{u x}$ are the parameters for memory cell value and input data respectively during the update step.

Finally $c^{<t>}$ value can be overwritten as in Equation (16)

$c^{<t>}:=\Gamma_{u} \hat{c}^{<t>}+\left(1-\Gamma_{u}\right) c^{<t-1>}$.

In the case of $\Gamma_{u}$ is equal to $1, c^{<t>}=\hat{c}^{<t>}$ meaning that update $c^{<t>}$, otherwise $c^{<t>}=c^{<t>}$ meaning 
that do not update. Now, we can extend the GRU structure as being an LSTM network. The assumption $c^{<t>}=a^{<t>}$ will be removed and two new parameters $\Gamma_{f}$ and $\Gamma_{o}$ named as forget gate and output gate respectively will be added. The revised formulation of the LSTM is shown in Equations (17)-(22)

$$
\begin{aligned}
& \hat{c}^{<t>}=g\left(W_{c a} a^{<t-1>}+W_{c x} x^{<t>}+b_{c}\right) \\
& \Gamma_{u}=g\left(W_{u a} a^{<t-1>}+W_{u x} x^{<t>}+b_{u}\right) \\
& \Gamma_{f}=g\left(W_{f a} a^{<t-1>}+W_{f x} x^{<t>}+b_{f}\right) \\
& \Gamma_{o}=g\left(W_{o a} a^{<t-1>}+W_{o x} x^{<t>}+b_{o}\right) \\
& c^{<t>}=\Gamma_{u} \hat{c}^{<t>}+\Gamma_{f} c^{<t-1>} \\
& a^{<t>}=\Gamma_{o} c^{<t>} .
\end{aligned}
$$

Instead of calculating $c^{<t>}$ based on Equation (16), we imply the formula given in Equation (17) and activation $a^{<t>}$ is calculated based on Equation (22) instead of equalling it to $c^{<t>}$. The simple structure of the LSTM cell is shown in Figure 4.

\begin{tabular}{|c|c|c|c|c|c|c|c|c|c|c|c|c|c|}
\hline & \multicolumn{5}{|c|}{ MLP } & \multicolumn{4}{|c|}{ SVM } & \multicolumn{4}{|c|}{ LSTM } \\
\hline & Method & & Opening & & Closing & & Opening & & Closing & & Opening & & Closing \\
\hline \multirow[t]{3}{*}{ AKBNK } & RMSE & \multirow{3}{*}{ 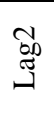 } & 0,27463 & \multirow{3}{*}{ 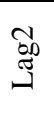 } & 0,17431 & \multirow{3}{*}{ 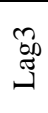 } & 0,31276 & \multirow{3}{*}{ 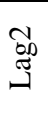 } & 0,24007 & \multirow{3}{*}{ 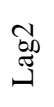 } & 0,28089 & \multirow{3}{*}{ 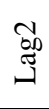 } & 0,17424 \\
\hline & MSE & & 0,07542 & & 0,03038 & & 0,09782 & & 0,05763 & & 0,07890 & & 0,03036 \\
\hline & R-square & & 0,96449 & & 0,98588 & & 0,98738 & & 0,99267 & & 0,96291 & & 0,98589 \\
\hline \multirow[t]{3}{*}{ AKSA } & RMSE & \multirow{3}{*}{ 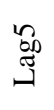 } & 0,90378 & \multirow{3}{*}{ 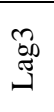 } & 0,28569 & \multirow{3}{*}{ 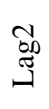 } & 1,69791 & \multirow{3}{*}{ 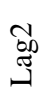 } & 1,61261 & \multirow{3}{*}{ త్ర } & 0,86830 & \multirow{3}{*}{ 志 } & 0,28526 \\
\hline & MSE & & 0,81682 & & 0,08162 & & 2,88291 & & 2,60050 & & 0,75394 & & 0,08137 \\
\hline & R-square & & 0,83902 & & 0,98269 & & 0,79320 & & 0,77006 & & 0,83863 & & 0,98277 \\
\hline \multirow[t]{3}{*}{ ALARK } & RMSE & \multirow{3}{*}{ 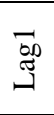 } & 0,46026 & \multirow{3}{*}{ 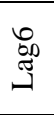 } & 0,16701 & \multirow{3}{*}{ 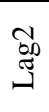 } & 0,74782 & \multirow{3}{*}{ 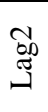 } & 0,58869 & \multirow{3}{*}{ 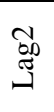 } & 0,41068 & \multirow{3}{*}{ 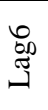 } & 0,16709 \\
\hline & MSE & & 0,21184 & & 0,02789 & & 0,55923 & & 0,34655 & & 0,16866 & & 0,02792 \\
\hline & R-square & & 0,92431 & & 0,99002 & & & & 0,95663 & & 0,93770 & & 0,99001 \\
\hline \multirow[t]{3}{*}{ AEFES } & RMSE & \multirow{3}{*}{ 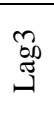 } & 0,58495 & \multirow{3}{*}{ త్ర0 } & 0,42600 & \multirow{3}{*}{ 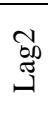 } & 0,59701 & \multirow{3}{*}{ 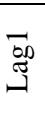 } & 0,43512 & \multirow{3}{*}{ 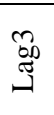 } & 0,53085 & \multirow{3}{*}{ مْ } & 0,42310 \\
\hline & MSE & & 0,34216 & & 0,18148 & & 0,35642 & & 0,18933 & & 0,28181 & & 0,17902 \\
\hline & R-square & & 0,94304 & & 0,97033 & & 0,98330 & & 0,99181 & & 0,95248 & & 0,97061 \\
\hline \multirow[t]{3}{*}{ ARCLK } & RMSE & & 0,75585 & & 0,42596 & & 1,60018 & & 1,26149 & & 0,62609 & & 0,33090 \\
\hline & MSE & ఝ & 0,57131 & ֻ & 0,18144 & ర్ల & 2,56058 & 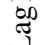 & 1,59135 & की & 0,39199 & ఝ & 0,10949 \\
\hline & R-square & & 0,96799 & ص & 0,97034 & & 0,95080 & & 0,97203 & & 0,97796 & 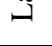 & 0,99389 \\
\hline ASELS & RMSE & & 1,59523 & & 0,98026 & & 7,17062 & & 6,49366 & & 1,60745 & & 0,97990 \\
\hline & MSE & మొ & 2,54475 & ర్తి & 0,96091 & 8 & 51,41780 & $\underset{7}{5}$ & 42,16761 & on & 2,58390 & ర్ల & 0,96021 \\
\hline & R-square & & 0,90443 & & 0,96212 & & 0,10905 & & 0,30025 & & 0,90181 & & 0,96209 \\
\hline BIMAS & RMSE & $\stackrel{\widetilde{J}}{\lrcorner}$ & 1,61346 & $\stackrel{\widetilde{J}}{\Xi}$ & 1,09490 & $\stackrel{\widetilde{J}}{త}$ & 1,59721 & $\stackrel{\widetilde{J}}{\lrcorner}$ & 1,36570 & $\stackrel{\tilde{J}}{\lrcorner}$ & 1,49377 & $\stackrel{\pi}{ت}$ & 1,09323 \\
\hline
\end{tabular}

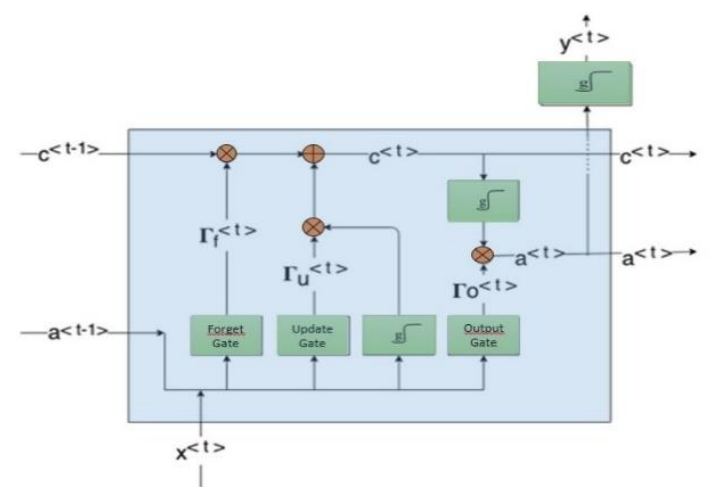

Figure 4. The structure of LSTM model. $\otimes=$ element-wise multiplication and $\bigoplus=$ summation processes

\section{THE RESEARCH FINDINGS AND DISCUSSION}

The results of the accuracy measures calculated for the estimates of the models are shown in Table 2.

Table 2. Results of MLP, SVM, and LSTM models 


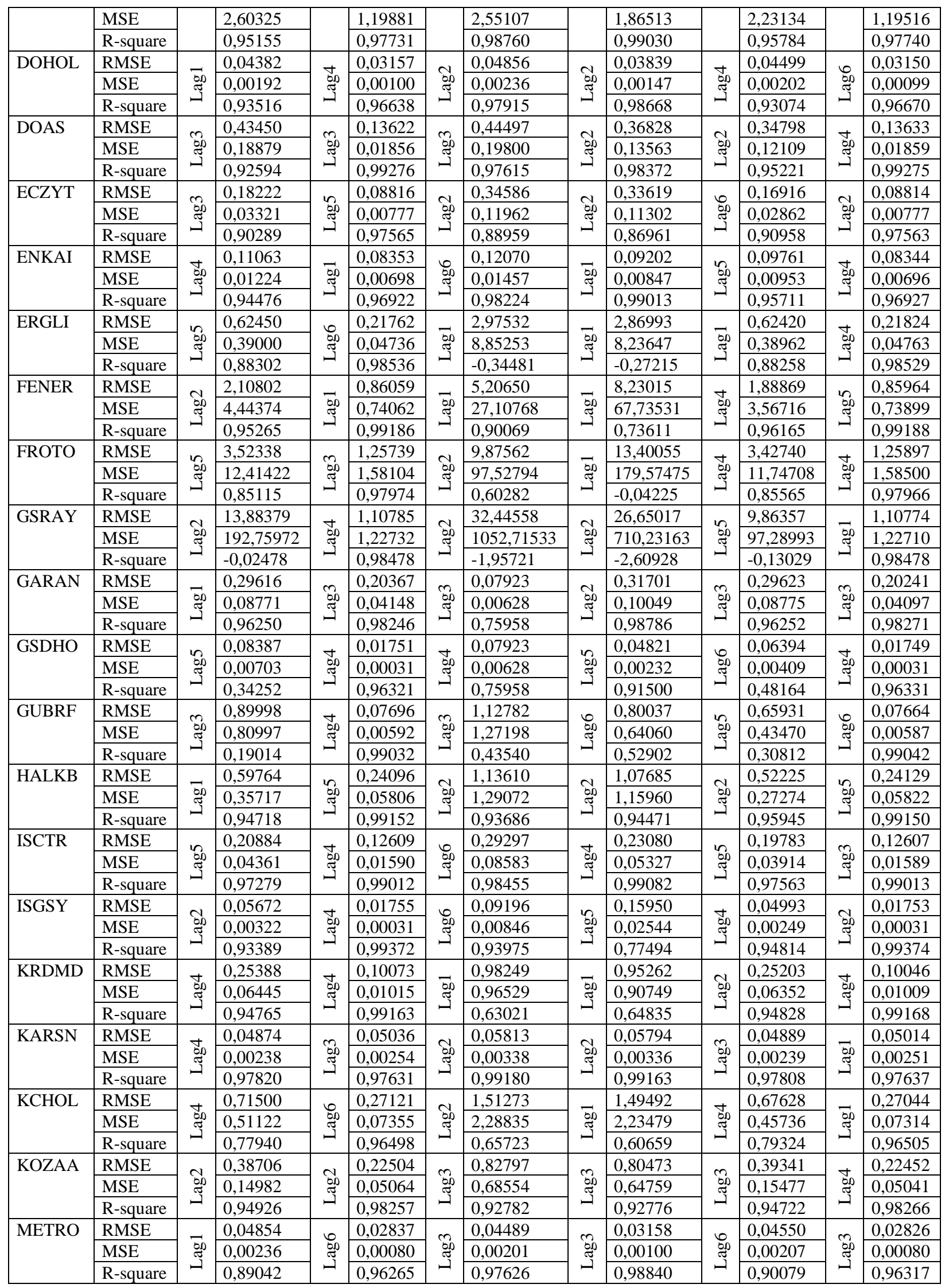




\begin{tabular}{|c|c|c|c|c|c|c|c|c|c|c|c|c|c|}
\hline \multirow[t]{3}{*}{ MGROS } & RMSE & \multirow{3}{*}{$\begin{array}{l}\infty \\
\underset{\Xi}{0} \\
\Xi\end{array}$} & 0,93954 & \multirow{3}{*}{ 吕 } & 0,46614 & \multirow{3}{*}{$\stackrel{5}{\leftrightarrows}$} & 1,05315 & \multirow{3}{*}{ త్ } & 0,76614 & \multirow{3}{*}{ త్ర } & 0,83635 & \multirow{3}{*}{ 必 } & 0,46568 \\
\hline & MSE & & 0,88274 & & 0,21728 & & 1,10911 & & 0,58697 & & 0,69948 & & 0,21686 \\
\hline & R-square & & 0,96079 & & 0,99056 & & 0,98650 & & 0,99345 & & 0,96878 & & 0,99059 \\
\hline \multirow[t]{3}{*}{ NETAS } & RMSE & \multirow{3}{*}{ త్ర } & 7,77737 & \multirow{3}{*}{ 吕 } & 0,32402 & \multirow{3}{*}{ 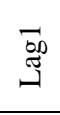 } & 7,69263 & \multirow{3}{*}{ ב్ } & 7,77190 & \multirow{3}{*}{ 茎 } & 5,77036 & \multirow{3}{*}{ 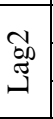 } & 0,32366 \\
\hline & MSE & & 60,48748 & & 0,10499 & & 59,17651 & & 60,40237 & & 33,29710 & & 0,10476 \\
\hline & R-square & & $-0,62799$ & & 0,98871 & & 0,49865 & & $-2,62104$ & & $-2,40533$ & & 0,98869 \\
\hline \multirow[t]{3}{*}{ PETKM } & RMSE & \multirow{3}{*}{ 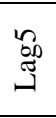 } & 0,20671 & \multirow{3}{*}{ 吕 } & 0,13671 & \multirow{3}{*}{$\stackrel{\infty}{\Xi}$} & 0,26157 & & 0,22806 & & 0,20697 & & 0,13715 \\
\hline & MSE & & 0,04273 & & 0,01869 & & 0,06842 & 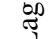 & 0,05201 & $\approx$ & 0,04284 & జ్ & 0,01881 \\
\hline & R-square & & 0,96706 & & 0,98528 & & 0,98591 & & 0,98843 & & 0,96700 & 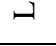 & 0,98520 \\
\hline SAHOL & RMSE & & 0,25282 & & 0,15625 & & 0,24520 & & 0,17673 & & 0,24244 & & 0,15542 \\
\hline & MSE & שֶ & 0,06392 & $\infty$ & 0,02441 & 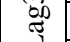 & 0,06012 & ळid & 0,03123 & $\approx$ & 0,05877 & 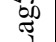 & 0,02415 \\
\hline & R-square & & 0,96535 & & 0,98679 & & 0,99148 & & 0,99571 & & 0,96821 & & 0,98691 \\
\hline SISE & MSE & & 0,26250 & & 0,20919 & & 0,62501 & & 0,42362 & & 0,26001 & & 0,21045 \\
\hline & MSE & סָ & 0,06891 & (5) & 0,04376 & ఝై & 0,39064 & מָ & 0,17946 & 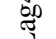 & 0,06761 & 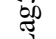 & 0,04429 \\
\hline & R-square & & 0,74140 & & 0,82766 & & 0,28107 & & 0,65576 & & 0,74117 & - & 0,82445 \\
\hline TSGYO & RMSE & & 0,10308 & & 0,02 & & 0,29 & & 0,20 & & 905 & & 2544 \\
\hline & MSE & סָ & 0,01063 & $\infty$ & 0,00065 & జ్ & 0,08428 & 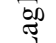 & 0,04378 & $\infty$ & 0,00793 & so & 0,00065 \\
\hline & R-square & 七 & 0,88816 & 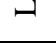 & 0,99308 & - & 0,65187 & & 0,82113 & & 0,91191 & 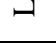 & 0,99310 \\
\hline TAVHL & RMSE & & 1,19369 & & 0,59178 & & 2,01652 & & 2,02184 & & 1,16661 & & 0,59295 \\
\hline & & $\stackrel{0}{\infty}$ & 1,42489 & $\infty$ & 0,35021 & ס & 4,06 & 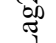 & 4,08 & $\approx 0$ & 1,36098 & (5) & 0,35159 \\
\hline & R-square & - & 0,91663 & ح & 0,97905 & 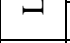 & 0,92029 & 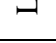 & 0,91248 & ص & 0,91913 & - & 0,97895 \\
\hline TKFEN & RMSE & & 0,94140 & & 0,40458 & & 7,82695 & & 7,46973 & & 0,95855 & & 0,40448 \\
\hline & MSE & 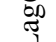 & 0,88623 & $\underset{\varpi}{\infty}$ & 0,16369 & ్ָ & 61,26 & 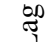 & 55,79687 & פ్ & 0,91881 & ๘) & 0,16360 \\
\hline & square & & 0,95289 & 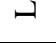 & 0,99122 & 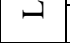 & $-1,23969$ & 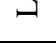 & $-0,99053$ & 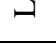 & 0,95064 & - & 0,99123 \\
\hline TOASO & RMSE & & 1,81918 & & 0,47735 & & 3,08997 & & 3,11582 & & 1,72115 & & 0,47403 \\
\hline & & 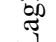 & & ๘ & 0,22786 & si & 9,54790 & 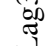 & 9,70834 & 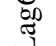 & 2,96236 & $\stackrel{5}{3}$ & 0,22471 \\
\hline & R-square & & 0,85766 & & 0,98974 & & 0,87800 & & 0,83419 & & 0,86375 & ○ & 0,98982 \\
\hline TRKCM & RMSE & & 0,15569 & & 0,09227 & & 0,55595 & & 0,46875 & & 0,14212 & & 0,09229 \\
\hline & MSE & 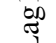 & 2424 & $\approx$ & 0,00851 & 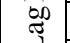 & 0,30908 & 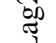 & 0,21972 & "్d & 0,02020 & 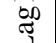 & 0,00852 \\
\hline & R-square & & 0,92784 & & 0,97408 & & 0,63393 & & 0,73563 & & 835 & & 0,97408 \\
\hline TUPRS & RMSE & & 5,92613 & & 2,45314 & & 23,51079 & & 23,22553 & & 6,53149 & & 2,44413 \\
\hline & MSE & 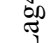 & 35,11898 & 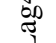 & 6,01791 & 必 & 552,75745 & 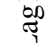 & 539,42505 & $\pi$ & 42,66032 & 5 & 5,97379 \\
\hline & $\mathrm{R}$ & & 0,81766 & 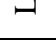 & 0,96634 & & & & & 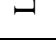 & 397 & - & 0,96633 \\
\hline THYAO & RMSE & & 0,95290 & & 0,70796 & & 4,157 & & 4,10337 & & 0,91524 & & 0,70845 \\
\hline & MSE & 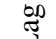 & 0,90802 & జ్ర & 0,50120 & \$ & 17,28437 & so & 16,83765 & $\approx 0$ & 0,83766 & 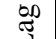 & 0,50190 \\
\hline & R-square & & 0,95217 & & 0,97318 & & 0,58631 & & 0,58923 & & 0,95554 & & 0,97314 \\
\hline TTKOM & RMSE & & 0,23473 & & 0,11734 & & 0,478 & & 0,46584 & & 0,23717 & & 1733 \\
\hline & MSE & $\approx$ & 0,05510 & 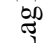 & 0,01377 & \$ & 0,22883 & $\underset{\pi}{50}$ & 0,21700 & 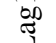 & 0,05625 & 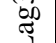 & 0,01377 \\
\hline & R-square & & 0,95904 & & 0,98985 & & 0,94111 & & 0,94517 & & 0,95795 & & 0,98985 \\
\hline & RMSE & & 0,29766 & & 0,26035 & & 0,44667 & & 0,43790 & & 0,29662 & & 0,26003 \\
\hline TCELL & MSE & 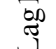 & 0,08860 & 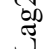 & 0,06778 & 5 & 0,19951 & 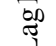 & 0,19175 & 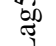 & 0,08798 & 类 & 0,06761 \\
\hline & ( & & 0,95939 & & 0,96857 & & 0,97382 & & 0,97397 & & 0,95945 & & 0,96858 \\
\hline VAKBN & RMSE & & 0,22085 & & 0,12277 & & 0,29220 & & 0,25462 & & 0,22263 & & 0,12226 \\
\hline & MSE & $\pi$ & 0,04878 & 幽 & 0,01507 & 幽 & 0,08538 & 5 & 0,06483 & $\pi$ & 0,04956 & $\stackrel{\infty 00}{\pi}$ & 0,01495 \\
\hline & & & & & 0,99076 & & 0,98495 & & 0,98893 & & 0,96948 & & 0,99085 \\
\hline YKBNK & RMSE & & 0,22209 & & 0,09537 & & 0,42522 & & 0,41442 & & 0,22301 & & 0,09540 \\
\hline & MSE & 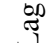 & 0,04932 & ๘ & 0,00910 & 必 & 0,18081 & \$) & 0,17175 & $\frac{50}{7}$ & 0,04973 & ֻ & 0,00910 \\
\hline & R-square & & 0,96465 & & 0,99353 & & 0,95679 & & 0,95862 & & 0,96453 & & 0,99353 \\
\hline
\end{tabular}

The most important result of the presented measurements is that all measurements show the MLP and LSTM models as the most accurate forecasting models. These results are supported using some basic statistics. Tables (2)-(4) show the basic statistics of forecasting errors. Statistical analyses were performed with the help of IBM SPSS Statistics software and a two-tailed t-test analysis was used to determine whether there was any difference between the groups. 
Table 3. Two-Tailed T-test Results for MLP

This table reports the statistics for the daily stock prices of the companies listed in BIST100 index (01/01/2010-01/01/2019)

\begin{tabular}{|c|c|c|c|c|c|c|c|c|c|c|c|c|}
\hline & \multicolumn{6}{|c|}{ Results for Opening Stock Prices } & \multicolumn{6}{|c|}{ Results for Closing Stock Prices } \\
\hline Companies & $\mathrm{N}$ & Corr. & Sig. & $\mathrm{t}$ & df & $\begin{array}{c}\text { Sig. } \\
\text { (2-tailed) }\end{array}$ & $\mathrm{N}$ & Corr. & Sig. & $\mathrm{t}$ & $\mathrm{df}$ & $\begin{array}{c}\text { Sig. } \\
\text { (2-tailed) }\end{array}$ \\
\hline AKBNK & 449 & ,982 & 000 &,- 360 & 448 &, 719 & 449 & ,993 & , 000 &,- 003 & 448 & ,998 \\
\hline AKSA & 449 & ,920 & 000 & 1,043 & 448 & ,297 & 450 & ,991 &, 000 &,- 593 & 449 &, 553 \\
\hline ALARK & 449 & ,962 & 000 & ,369 & 448 & ,712 & 448 & ,995 & 000 &,- 012 & 447 & 991 \\
\hline AEFES & 449 & ,972 &, 000 &,- 753 & 448 & 452 & 449 & ,985 & 000 &,- 005 & 448 & ,996 \\
\hline ARCLK & 449 & ,984 & 000 &,- 471 & 448 &, 638 & 449 & ,985 & 000 &, 101 & 448 & ,920 \\
\hline ASELS & 449 & ,952 &, 000 &,- 322 & 448 & ,748 & 449 & ,981 & ,000 & ,409 & 448 & ,683 \\
\hline BIMAS & 449 & ,976 &, 000 &, 372 & 448 &, 710 & 449 & ,989 &, 000 & 1,387 & 448 &, 166 \\
\hline DOHOL & 449 & ,968 &, 000 & 1,062 & 448 & ,289 & 449 & ,983 &, 000 & ,348 & 448 & ,728 \\
\hline DOAS & 449 & 963 & ,000 &, 357 & 448 & 721 & 449 & ,996 & 000 &,- 324 & 448 & ,746 \\
\hline ECZYT & 449 & ,952 &, 000 & 1,241 & 448 &, 215 & 449 & ,988 & 000 & ,094 & 448 & ,925 \\
\hline ENKAI & 449 & ,972 & 000 &,- 157 & 448 & 875 & 449 & ,985 & ,000 &,- 012 & 448 & ,991 \\
\hline ERGLI & 449 & ,941 &, 000 &,- 149 & 448 &, 882 & 448 & ,993 &, 000 & ,355 & 447 & ,723 \\
\hline FENER & 449 & 977 & ,000 &,- 993 & 448 &, 321 & 449 & ,996 & 000 &,- 088 & 448 & ,930 \\
\hline FROTO & 449 & ,925 & 000 &, 167 & 448 & 867 & 449 & ,990 &, 000 &, 371 & 448 &, 711 \\
\hline GSRAY & 449 & ,487 &, 000 & ,008 & 448 & ,994 & 449 & ,992 &, 000 & 008 & 448 & ,994 \\
\hline GARAN & 449 & ,981 &, 000 &,- 132 & 448 &, 895 & 449 & ,991 &, 000 &,- 164 & 448 &, 870 \\
\hline GSDHO & 449 & 671 & 000 &, 323 & 448 &, 747 & 449 & 982 & 000 & ,316 & 448 & 752 \\
\hline GUBRF & 449 & ,596 & 000 &, 007 & 448 & ,994 & 448 & ,995 &, 000 &, 001 & 447 & ,999 \\
\hline HALKB & 449 & ,974 & ,000 &,- 015 & 448 & ,988 & 449 & ,996 & ,000 & ,642 & 448 & ,521 \\
\hline ISCTR & 449 & ,986 &, 000 &,- 383 & 448 & ,702 & 449 & ,995 &, 000 &,- 002 & 448 & ,998 \\
\hline ISGSY & 449 & 967 & 000 & $-1,837$ & 448 & 067 & 449 & ,997 & 000 &, 026 & 448 & 979 \\
\hline KRDMD & 449 & 974 &, 000 &, 229 & 448 & 819 & 449 & ,996 & 000 &, 145 & 448 & 885 \\
\hline KARSN & 449 & ,989 &, 000 & $-1,166$ & 448 &, 244 & 449 & ,988 &, 000 &,- 268 & 448 & 789 \\
\hline KCHOL & 449 & 890 &, 000 &, 001 & 448 & ,999 & 448 & ,983 &, 000 &,- 590 & 447 &, 555 \\
\hline KOZAA & 449 & 975 & ,000 & 1,274 & 448 & ,203 & 449 & ,991 & 000 & 1,240 & 448 & ,216 \\
\hline METRO & 449 & ,945 &, 000 &, 448 & 448 &, 655 & 448 & ,981 &, 000 &,- 148 & 447 & 883 \\
\hline MGROS & 449 & 980 & 000 &, 704 & 448 & 482 & 449 & ,995 &, 000 &,- 274 & 448 &, 784 \\
\hline NETAS & 449 &, 187 &, 000 &, 004 & 448 & ,997 & 448 & ,994 &, 000 &, 143 & 447 & ,886 \\
\hline PETKM & 449 & ,984 &, 000 &, 414 & 448 & 679 & 449 & ,993 &, 000 &, 146 & 448 & ,884 \\
\hline SAHOL & 449 & ,983 &, 000 &,- 236 & 448 & 814 & 449 & ,993 & 000 &,- 584 & 448 & 559 \\
\hline SISE & 449 & 871 &, 000 &, 268 & 448 &, 788 & 448 & ,914 &, 000 &, 024 & 447 & 981 \\
\hline TSGYO & 449 & ,944 & ,000 & $-1,347$ & 448 & 179 & 449 & ,997 & ,000 &,- 005 & 448 & ,996 \\
\hline TAVHL & 449 & ,958 &, 000 &,- 804 & 448 &, 422 & 449 & ,990 &, 000 &, 199 & 448 & ,843 \\
\hline TKFEN & 448 & ,976 & 000 & ,910 & 447 &, 363 & 449 & ,996 & 000 & ,938 & 448 & 349 \\
\hline TOASO & 449 & ,929 &, 000 &, 175 & 448 & 861 & 449 & ,995 &, 000 &,- 179 & 448 & 858 \\
\hline TRKCM & 449 & ,964 &, 000 & ,137 & 448 & ,891 & 449 & ,987 &, 000 &,- 008 & 448 & ,994 \\
\hline TUPRS & 449 & ,910 &, 000 &,- 980 & 448 &, 328 & 449 & ,983 &, 000 & ,209 & 448 & ,834 \\
\hline THYAO & 449 & ,976 &, 000 &, 733 & 448 & ,464 & 449 & ,987 & ,000 & ,580 & 448 & ,562 \\
\hline TTKOM & 449 & 980 & ,000 &,- 177 & 448 &, 860 & 449 & ,995 &, 000 & 170 & 448 & 865 \\
\hline TCELL & 449 & ,980 &, 000 &,- 019 & 448 & ,985 & 449 & ,984 & 000 &,- 084 & 448 & ,933 \\
\hline VAKBN & 449 & ,985 &, 000 &,- 501 & 448 & ,616 & 449 & ,995 &, 000 &,- 288 & 448 &, 773 \\
\hline YKBNK & 449 & ,982 &, 000 &,- 193 & 448 & 847 & 449 & ,997 &, 000 &,- 107 & 448 & 915 \\
\hline
\end{tabular}

When the $t$ values and $\mathrm{P}$ values obtained as a result of the difference analysis between the actual and forecast values of the companies are examined, it is seen that the $\mathrm{H}_{0}$ hypotheses which support the absence of any difference are supported. In addition, the correlation values also confirm this indifference with values close to 1 . The consistency of the predicted values obtained as a result of the MLP analysis was also supported by statistical difference analysis. According to the information obtained from Table 3, the hypotheses established for the MLP model are as follows;

$H_{0}: \mu 1$ to $\mu 2=0, H_{1}: \mu 1$ to $\mu 2 \neq 0$ 
Opening $\quad p$-value $=$ Sig. $(2$-tailed $)=0.650690$

Closing $\quad p$-value $=$ Sig. $(2$-tailed $)=0.798048$

Prices Since the $\mathrm{p}$-value $=0.650690>0.05=\alpha$, Prices Since the $\mathrm{p}$-value $=0.798048>0.05=$ the absence hypothesis is accepted. $\alpha$, the absence hypothesis is accepted.

Table 4. Two-Tailed T-test Results for SVM

This table reports the statistics for the daily stock prices of the companies listed in BIST100 index (01/01/2010-01/01/2019)

\begin{tabular}{|c|c|c|c|c|c|c|c|c|c|c|c|c|}
\hline & \multicolumn{6}{|c|}{ Results for Opening Stock Prices } & \multicolumn{6}{|c|}{ Results for Closing Stock Prices } \\
\hline Companies & $\mathrm{N}$ & Corr. & Sig. & $\mathrm{t}$ & df & $\begin{array}{c}\text { Sig. } \\
\text { (2-tailed) }\end{array}$ & $\mathrm{N}$ & Corr. & Sig. & $\mathrm{t}$ & df & $\begin{array}{c}\text { Sig. } \\
\text { (2-tailed) }\end{array}$ \\
\hline AKBNK & 449 & ,996 &, 000 & 7,585 & 448 &, 000 & 449 & ,998 &, 000 & 8,864 & 448 &, 000 \\
\hline AKSA & 449 & ,978 &, 000 & 25,395 & 448 & 000 & 450 & ,997 & ,000 & 33,420 & 449 & 000 \\
\hline ALARK & 449 & ,990 &, 000 & 4,918 & 448 & ,000 & 450 & ,999 &, 000 & 9,053 & 449 &, 000 \\
\hline AEFES & 449 & ,994 &, 000 & 3,113 & 448 & ,002 & 450 & ,996 &, 000 & 1,578 & 449 &, 115 \\
\hline ARCLK & 449 & ,995 &, 000 & 9,986 & 448 & ,000 & 450 & ,999 & , 000 & 17,408 & 449 & ,000 \\
\hline ASELS & 449 & ,986 &, 000 & 46,057 & 448 & , 000 & 449 & ,990 &, 000 & 48,903 & 448 &, 000 \\
\hline BIMAS & 449 & ,994 &, 000 & 3,927 & 448 &, 000 & 450 & ,997 &, 000 & 8,208 & 449 & 000 \\
\hline DOHOL & 449 & ,990 &, 000 & 3,231 & 448 & ,001 & 449 & ,994 &, 000 & 3,869 & 448 & ,000 \\
\hline DOAS & 449 & ,994 &, 000 & $-2,230$ & 448 &, 026 & 449 & ,999 &, 000 & 5,850 & 448 &, 000 \\
\hline ECZYT & 449 & ,989 &, 000 & 29,291 & 448 & , 000 & 449 & ,996 &, 000 & 24,452 & 448 & , 000 \\
\hline ENKAI & 449 & ,993 & ,000 & 9,272 & 448 & ,000 & 450 & ,996 &, 000 & 8,205 & 449 & ,000 \\
\hline ERGLI & 450 & ,984 &, 000 & 49,738 & 449 &, 000 & 450 & ,998 &, 000 & 52,801 & 449 &, 000 \\
\hline FENER & 450 & ,993 &, 000 & $-23,727$ & 449 & ,000 & 450 & ,999 & , 000 & $-50,404$ & 449 & ,000 \\
\hline FROTO & 449 & ,981 &, 000 & 49,131 & 448 &, 000 & 450 & ,997 &, 000 & 57,502 & 449 &, 000 \\
\hline GSRAY & 449 &, 867 &, 000 & $-53,655$ & 448 &, 000 & 449 & ,998 &, 000 & $-139,394$ & 448 & 000 \\
\hline GARAN & 449 & ,994 &, 000 & 7,886 & 448 &, 000 & 449 & ,997 &, 000 & 7,087 & 448 & 000 \\
\hline GSDHO & 449 & ,933 &, 000 & $-11,423$ & 448 & ,000 & 449 & ,995 &, 000 & $-36,323$ & 448 & 000 \\
\hline GUBRF & 449 & ,908 & ,000 & $-23,317$ & 448 & ,000 & 448 & ,998 & , 000 & $-36,094$ & 447 & ,000 \\
\hline HALKB & 449 & ,994 &, 000 & $-18,908$ & 448 & ,000 & 449 & ,998 &, 000 & $-23,457$ & 448 & ,000 \\
\hline ISCTR & 449 & ,997 &, 000 & 11,393 & 448 &, 000 & 449 & ,998 &, 000 & 12,315 & 448 &, 000 \\
\hline ISGSY & 449 & ,992 &, 000 & $-12,565$ & 448 & ,000 & 449 & ,999 &, 000 & $-23,074$ & 448 & ,000 \\
\hline KRDMD & 450 & ,993 &, 000 & 25,255 & 449 &, 000 & 450 & ,999 &, 000 & 25,903 & 449 &, 000 \\
\hline KARSN & 449 & ,996 &, 000 & 2,614 & 448 & ,009 & 449 & ,997 &, 000 & $-6,288$ & 448 & ,000 \\
\hline KCHOL & 449 &, 975 &, 000 & 38,681 & 448 &, 000 & 450 &, 995 &, 000 & 52,421 & 449 &, 000 \\
\hline KOZAA & 449 & ,993 &, 000 & 27,365 & 448 &, 000 & 449 & ,996 &, 000 & 27,211 & 448 & 000 \\
\hline METRO & 449 & ,988 & ,000 & $-3,232$ & 448 & ,001 & 449 & ,995 & , 000 & $-7,636$ & 448 &, 000 \\
\hline MGROS & 449 & ,995 &, 000 & $-7,075$ & 448 &, 000 & 449 & ,998 &, 000 & $-16,813$ & 448 &, 000 \\
\hline NETAS & 450 &, 768 &, 000 & $-9,310$ & 449 & 000 & 449 & ,998 &, 000 & $-78,313$ & 448 & 000 \\
\hline PETKM & 449 & ,996 &, 000 & 16,091 & 448 & ,000 & 450 & ,998 &, 000 & $-15,301$ & 449 & ,000 \\
\hline SAHOL & 449 & ,996 &, 000 & $-2,081$ & 448 &, 038 & 449 & ,998 &, 000 & 2,194 & 448 &, 029 \\
\hline SISE & 449 & ,966 &, 000 & 31,914 & 448 &, 000 & 449 & ,975 &, 000 & 17,693 & 448 & , 000 \\
\hline TSGYO & 450 & ,985 &, 000 & $-35,265$ & 449 &, 000 & 450 & ,999 &, 000 & $-30,383$ & 449 & 000 \\
\hline TAVHL & 449 & ,986 &, 000 & 15,200 & 448 &, 000 & 449 & ,996 &, 000 & 19,488 & 448 &, 000 \\
\hline TKFEN & 450 & ,993 &, 000 & 42,328 & 449 & ,000 & 450 & ,999 &, 000 & 42,083 & 449 & ,000 \\
\hline TOASO & 449 & ,983 &, 000 & 28,790 & 448 &, 000 & 449 & ,996 &, 000 & 26,835 & 448 &, 000 \\
\hline TRKCM & 450 & ,990 &, 000 & 37,150 & 449 &, 000 & 449 & ,995 &, 000 & 33,213 & 448 &, 000 \\
\hline TUPRS & 450 & ,970 &, 000 & 55,089 & 449 &, 000 & 450 & ,996 &, 000 & 68,724 & 449 & 000 \\
\hline THYAO & 450 & ,994 &, 000 & 30,643 & 449 &, 000 & 450 & ,997 &, 000 & 31,174 & 449 &, 000 \\
\hline TTKOM & 450 & ,994 & , 000 & $-13,613$ & 449 & ,000 & 450 & ,999 &, 000 & $-17,802$ & 449 & ,000 \\
\hline TCELL & 449 & ,994 &, 000 & 14,965 & 448 & ,000 & 450 & ,996 &, 000 & 18,816 & 449 &, 000 \\
\hline VAKBN & 449 & ,996 &, 000 & 8,239 & 448 &, 000 & 449 & ,998 &, 000 & 13,909 & 448 & 000 \\
\hline YKBNK & 450 & ,995 &, 000 & $-11,394$ & 449 &, 000 & 450 & ,999 &, 000 & $-13,912$ & 449 &, 000 \\
\hline
\end{tabular}

When the $t$ values and $\mathrm{P}$ values obtained as a result of the difference analysis between the actual and forecast values of the companies are examined, it is seen that the $H_{0}$ hypotheses which do not show any difference are not supported. The inconsistency of the estimation values obtained as a result of SVM analysis was also supported by statistical difference analysis. The hypotheses established for the SVM model are as follows according to the information obtained from Table 4; 
$H_{0}: \mu 1$ to $\mu 2=0, H_{1}: \mu 1$ to $\mu 2 \neq 0$

Opening p-value $=$ Sig. $(2$-tailed $)=0.001833$ prices
Since the $\mathrm{p}$-value $=0.001833<0.05=\alpha$, prices the absence hypothesis is rejected.
Closing p-value $=$ Sig. $(2$-tailed $)=0.003429$ Since the $\mathrm{p}$-value $=0.003429<0.05=\alpha$, the absence hypothesis is rejected.

Table 5. Two-Tailed T-test Results for LSTM

This table reports the statistics for the daily stock prices of the companies listed in BIST100 index (01/01/2010-01/01/2019)

\begin{tabular}{|c|c|c|c|c|c|c|c|c|c|c|c|c|}
\hline & \multicolumn{6}{|c|}{ Results for Opening Stock Prices } & \multicolumn{6}{|c|}{ Results for Closing Stock Prices } \\
\hline Companies & $\mathrm{N}$ & Corr. & Sig. & $\mathrm{t}$ & $\mathrm{df}$ & $\begin{array}{c}\text { Sig. } \\
\text { (2-tailed) }\end{array}$ & $\mathrm{N}$ & Corr. & Sig. & $\mathrm{t}$ & $\mathrm{df}$ & $\begin{array}{c}\text { Sig. } \\
\text { (2-tailed) }\end{array}$ \\
\hline AKBNK & 449 & ,981 & 000 &,- 139 & 448 & ,889 & 449 & ,993 &, 000 &, 122 & 448 & ,903 \\
\hline AKSA & 449 & ,925 & 000 & $-1,538$ & 448 & , 125 & 449 & ,991 &, 000 &,- 064 & 448 & ,949 \\
\hline ALARK & 449 & ,973 &, 000 &,- 553 & 448 & ,580 & 448 & ,995 & ,000 &,- 155 & 447 & ,877 \\
\hline AEFES & 449 & ,976 & , 000 & ,469 & 448 & ,640 & 449 & ,985 & ,000 &, 073 & 448 & ,942 \\
\hline ARCLK & 449 & ,989 & ,000 & ,334 & 448 & ,738 & 448 & ,997 & ,000 &,- 660 & 447 & ,510 \\
\hline ASELS & 449 & ,951 &, 000 &, 584 & 448 & ,559 & 449 & ,981 &, 000 &, 025 & 448 & ,980 \\
\hline BIMAS & 449 & 979 & ,000 & ,088 & 448 & ,930 & 449 & ,989 & ,000 &,- 059 & 448 & ,953 \\
\hline DOHOL & 449 & ,965 &, 000 &,- 410 & 448 & ,682 & 448 & ,983 &, 000 &, 165 & 447 &, 869 \\
\hline DOAS & 449 & ,976 & ,000 & ,964 & 448 & ,336 & 449 & ,996 &, 000 & ,208 & 448 &, 835 \\
\hline ECZYT & 448 & ,958 &, 000 &,- 398 & 447 & ,691 & 449 & ,988 &, 000 &,- 001 & 448 & ,999 \\
\hline ENKAI & 449 & 979 & ,000 &, 652 & 448 &, 515 & 449 & ,985 &, 000 &,- 067 & 448 & ,947 \\
\hline ERGLI & 449 & ,941 & , 000 & ,366 & 448 & ,715 & 449 & ,993 & ,000 &,- 115 & 448 & ,909 \\
\hline FENER & 449 & ,981 & ,000 &,- 379 & 448 & ,705 & 449 & ,996 & ,000 &, 121 & 448 & ,904 \\
\hline FROTO & 449 & ,929 &, 000 & 1,244 & 448 & ,214 & 449 & ,990 &, 000 &, 129 & 448 &, 898 \\
\hline GSRAY & 449 & ,694 & ,000 &,- 151 & 448 & ,880 & 449 & ,992 & ,000 & ,204 & 448 & ,838 \\
\hline GARAN & 449 & ,981 &, 000 &, 452 & 448 & ,651 & 449 & ,991 &, 000 &, 012 & 448 & ,990 \\
\hline GSDHO & 448 & ,790 & , 000 & 1,678 & 447 & ,094 & 449 & ,982 &, 000 &,- 200 & 448 & ,842 \\
\hline GUBRF & 449 & ,757 &, 000 & 2,275 & 448 &, 023 & 448 & ,995 &, 000 &,- 079 & 447 & ,937 \\
\hline HALKB & 449 & ,980 &, 000 &, 652 & 448 &, 515 & 449 & ,996 &, 000 &, 060 & 448 & 952 \\
\hline ISCTR & 449 & ,988 & ,000 &,- 314 & 448 & ,754 & 449 & ,995 & ,000 & ,026 & 448 & ,979 \\
\hline ISGSY & 449 & ,974 & , 000 &, 345 & 448 & ,730 & 449 & ,997 &, 000 &,- 306 & 448 & ,760 \\
\hline KRDMD & 449 & ,974 &, 000 &, 550 & 448 &, 583 & 449 & ,996 &, 000 &, 066 & 448 & 947 \\
\hline KARSN & 449 & ,989 &, 000 &,- 458 & 448 & ,647 & 449 & ,988 &, 000 &, 132 & 448 &, 895 \\
\hline KCHOL & 449 & 900 & 000 &,- 084 & 448 & ,933 & 449 & ,983 &, 000 &,- 212 & 448 &, 832 \\
\hline KOZAA & 449 & ,974 & , 000 &, 737 & 448 & ,461 & 449 & ,991 &, 000 &,- 028 & 448 & ,978 \\
\hline METRO & 448 & ,951 &, 000 & 1,258 & 447 & ,209 & 449 & ,982 &, 000 &, 494 & 448 &, 622 \\
\hline MGROS & 449 & ,985 &, 000 &,- 597 & 448 & ,551 & 449 & ,995 &, 000 &,- 020 & 448 & ,984 \\
\hline NETAS & 448 & ,362 & ,000 &,- 721 & 447 & ,471 & 449 & ,994 & ,000 &, 243 & 448 & ,808 \\
\hline PETKM & 449 & ,983 & ,000 &,- 030 & 448 & ,976 & 449 & ,993 &, 000 &, 073 & 448 & ,942 \\
\hline SAHOL & 449 & ,984 &, 000 &,- 887 & 448 & ,376 & 449 & ,993 &, 000 &,- 339 & 448 &, 735 \\
\hline SISE & 449 & 872 &, 000 &, 508 & 448 & ,612 & 449 & ,913 &, 000 &,- 163 & 448 & 871 \\
\hline TSGYO & 449 & ,958 &, 000 &,- 325 & 448 &, 745 & 449 & ,997 &, 000 &,- 114 & 448 & ,909 \\
\hline TAVHL & 449 & ,960 &, 000 &,- 211 & 448 & ,833 & 449 & ,989 &, 000 &, 115 & 448 & ,908 \\
\hline TKFEN & 449 & ,976 & , 000 & 1,101 & 448 & ,272 & 449 & ,996 &, 000 & ,763 & 448 & ,446 \\
\hline TOASO & 448 & ,935 &, 000 &, 833 & 447 &, 405 & 449 & ,995 &, 000 & $-1,537$ & 448 &, 125 \\
\hline TRKCM & 448 & ,970 & ,000 & $-2,712$ & 447 & ,007 & 449 & ,987 & ,000 &, 160 & 448 &, 873 \\
\hline TUPRS & 449 & ,892 &, 000 & ,099 & 448 & ,921 & 448 & ,983 &, 000 &, 135 & 447 &, 893 \\
\hline THYAO & 449 & ,978 & , 000 & ,579 & 448 & ,563 & 449 & ,987 &, 000 &, 346 & 448 & ,729 \\
\hline TTKOM & 449 & ,979 &, 000 &,- 400 & 448 & ,690 & 449 & ,995 &, 000 &,- 174 & 448 &, 862 \\
\hline TCELL & 449 & 980 & ,000 &, 173 & 448 &, 862 & 449 & ,984 &, 000 &,- 202 & 448 &, 840 \\
\hline VAKBN & 449 & ,985 &, 000 &, 093 & 448 & ,926 & 449 & ,995 &, 000 &, 197 & 448 &, 844 \\
\hline YKBNK & 448 & ,982 &, 000 &,- 282 & 447 & ,778 & 449 & ,997 &, 000 &, 124 & 448 & ,901 \\
\hline
\end{tabular}

When the $t$ values and $\mathrm{P}$ values obtained as a result of the difference analysis between the real and forecast values of the companies are examined, it is seen that the $H_{0}$ hypotheses which support the absence of any 
difference are supported. In addition, the correlation values also confirm this indifference with values close to 1 . The consistency of the predicted values obtained as a result of LSTM analysis was also supported by statistical difference analysis. The hypotheses established for the LSTM model are as follows according to the information obtained from Table 5;

$$
H_{0}: \mu 1 \text { to } \mu 2=0, H_{1}: \mu 1 \text { to } \mu 2 \neq 0
$$

Opening $\quad p$-value $=$ Sig. $(2$-tailed $)=0.590167 \quad$ Closing $\quad$-value $=$ Sig. $(2$-tailed $)=0.850405$

prices Since the $\mathrm{p}$-value $=0.590167>0.05=\alpha$, prices the absence hypothesis is accepted.

Since the $\mathrm{p}$-value $=0.850405>0.05=\alpha$, the absence hypothesis is accepted.

\section{CONCLUSION}

This study attempted to forecast the opening and closing stock prices of 42 firms listed in the Istanbul Stock Exchange National 100 Index (ISE-100) using machine learning methods and deep learning algorithms. For this purpose, two well-known machine learning methods, Multilayer Perceptrons (MLP) and Support Vector Machines (SVM) models and deep learning algorithm, Long Short Term Memory (LSTM) were constructed and applied to the daily data from 2010 to 2019 by comparing their forecasting performances. The analysis includes 9 years of daily data from 01.01.2010 to 01.01.2019. For each firm 2249 data for the opening and 2249 data for the closing stock prices were established as daily data sets which make 188,196 data in total.

Multilayer Perceptrons (MLP) model as a type of artificial neural network method has been applied in many fields and it has been seen that it has achieved successful results in forecasting. The reason why this model has been preferred as an ANN method is that it gives easy, fast, flexible and consistent results. Another model Support Vector Machines (SVM) has been chosen in this study as it has been recently applied successfully in classification, regression and time series forecasting applications. LSTM (Long Short Term Memory) is the last model used in this study as a type of recurrent neural networks designed to recognize patterns in data sequences such as text, genomes, handwriting, spoken word or numerical time series data obtained from sensors, stock markets and government agencies, as it is one the most powerful and useful types of recurrent neural networks. The results show that the MLP model outperforms SVM and LSTM models in predicting the opening stock prices while the LSTM model outperforms MLP and SVM models in predicting the closing stock prices. In predicting both opening and closing stock prices, the SVM model has the worst forecasting performance among other models used in this study. Figure 5. illustrates Türkiye İş Bankası A.Ş. forecasted closing stock prices compared in three models on test dataset.
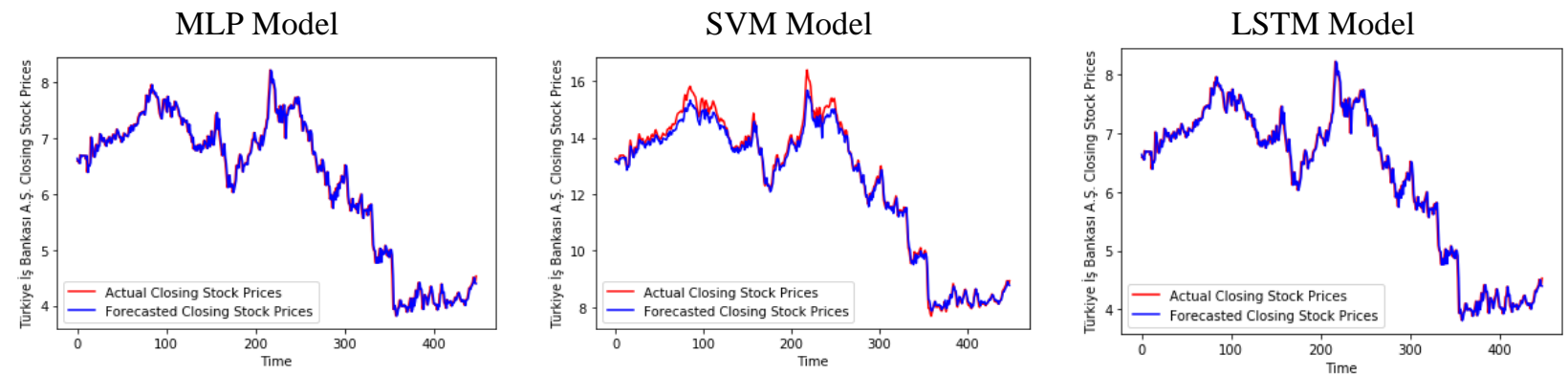

Figure 5. Türkiye İş Bankası A.Ş. Closing Stock Prices Forecast

When we look at the statistical measure for goodness-of-fit, it is observed that both MLP and LSTM models have a good fit. As seen in table 6 , the MLP model reached the highest $\left(\mathrm{R}^{2}\right)$ value $(0,831719 \%)$ in opening stock prices and $(0,977674 \%)$ in closing stock prices; and LSTM model reached the highest $\left(\mathrm{R}^{2}\right)$ value 
$(0,796815 \%)$ in opening stock prices and $(0,978206 \%)$ in closing stock prices. SVM model reached the lowest $\left(\mathrm{R}^{2}\right)$ values for both opening and closing stock prices $(0,66195 \%, 0,580348 \%$ respectively).

Table 6. $R$-squared $\left(\mathrm{R}^{2}\right)$ Results for MLP, SVM and LSTM Models (Averages)

\begin{tabular}{|c|c|c|}
\hline & Opening Values & Closing Values \\
\hline MLP & 0,831719 & 0,977674 \\
\hline SVM & 0,661956 & 0,580348 \\
\hline LSTM & 0,796815 & 0,978206 \\
\hline
\end{tabular}

In this study, two paired t-test was used for the analysis and the Sig (2-Tailed) value which is referred to as the p-value was preferred as 0.005 . With a $95 \%$ confidence interval, it was revealed that statistically there was no significant difference between the actual values and the forecasted values for both opening and closing stock prices according to the statistical results (Table 7) obtained from MLP and LSTM models.

Table 7. Two-Tailed T-test Results for MLP, SVM and LSTM Models (Averages)

\begin{tabular}{|c|c|c|}
\hline & Opening Values & Closing Values \\
\hline MLP & $0,650690 \%$ & $0,798048 \%$ \\
\hline SVM & $0,001833 \%$ & $0,003429 \%$ \\
\hline LSTM & $0,590167 \%$ & $0,850405 \%$ \\
\hline
\end{tabular}

The hypotheses were established as shown below:

$H_{0}: \mu 1-\mu 2=0, H_{1}: \mu_{1}-\mu_{2} \neq 0$

For opening stock prices;

MLP $\quad p$-value $=$ Sig. $(2$-tailed $)=0,650690$ Since $p$-value $=0,650690>0.05=\alpha$, we fail to reject the null hypothesis $p$-value $=$ Sig. $(2$-tailed $)=0,001833$

SVM Since $p$-value $=0,001833<0.05=\alpha$, we reject the null hypothesis

LSTM $p$-value $=$ Sig. $(2$-tailed $)=0,590167$ Since $p$-value $=0,590167>0.05=\alpha$, we fail to reject the null hypothesis
For closing stock prices;

MLP $\quad p$-value $=$ Sig. $(2$-tailed $)=0,798048$ Since $p$-value $=0,798048>0.05=\alpha$, we fail to reject the null hypothesis

SVM $\quad p$-value $=$ Sig. $(2$-tailed $)=0,003429$ Since $p$-value $=0,003429<0.05=\alpha$, we reject the null hypothesis

LSTM $p$-value $=$ Sig. $(2$-tailed $)=0,850405$ Since $p$-value $=0,850405>0.05=\alpha$, we fail to reject the null hypothesis

Overall, we can say that both MLP and LSTM models are useful in time series for predicting stock prices. However, as opposed to previous studies proposing that SVM is an alternative model for financial timeseries forecasting, this study concluded that SVM still needs to be enhanced for prediction applications. The results also showed that the more training cases we use; the better results we get in forecasting time series.

In future studies, it is believed that comparative analysis of MLP and LSTM models with other large scale data collected from various sectors and other methods used in time series forecasting applications will contribute to the literature in determining the effectiveness of MLP and LSTM models. The findings of these additional studies will lead us to several important models of forecasting financial time series.

\section{CONFLICTS OF INTEREST}

No conflict of interest was declared by the authors. 


\section{REFERENCES}

[1] Abu-Mostafa, Y. S., Atiya, A. F., "Introduction to financial forecasting", Applied Intelligence, 6(3): 205-213, (1996).

[2] Huang, W., Nakamori, Y., Wang S. Y., "Forecasting stock market movement direction with support vector machine", Computers and Operations Research, 32(10): 2513-2522, (2005).

[3] Kara, Y., Boyacioglu, M. A., Baykan, O. K., "Predicting direction of stock price index movement using artificial neural networks and support vector machines: The sample of the Istanbul Stock Exchange", Expert Systems with Applications, 38(5): 5311-5319, (2011).

[4] Northover, K., Lo, A. W., "Computational finance”, Computer in Science \& Engineering, 1(6): 22, (2000).

[5] Tan, T. Z., Quek, C., Ng, G. S., "Biological brain-inspired genetic complementary learning for stock market and bank failure prediction”, Computer Intelligence, 23(2): 236-261, (2007).

[6] Blank, S. C., "'Chaos' in futures markets? A nonlinear dynamical analysis", The Journal of Futures Markets, 11(6): 711, (1991).

[7] Zhang, G., Patuwo, B. E., Hu, M. Y., "Forecasting with artificial neural networks: The state of the art" International Journal of Forecasting, 14(1): 35-62, (1998).

[8] Lapedes, A., Farber, R., "Nonlinear signal processing using neural networks: Prediction and system modelling", 1. IEEE international conference on neural networks, San Diego, CA, USA, No. LA-UR87-2662; CONF-8706130-4, (1987).

[9] Gorr, W. L., Nagin, D., Szczypula, J., "Comparative study of artificial neural network and statistical models for predicting student grade point averages", International Journal of Forecasting, 10(1): 1734, (1994).

[10] Ruiz-Suarez, J., Mayora-Ibarra, O., Torres-Jimenez, J., Ruiz-Suarez, L., "Short-term ozone forecasting by artificial neural networks", Advances in Engineering Software, 23(3): 143-9, (1995).

[11] Kohzadi, N., Boyd, M. S., Kermanshahi, B., Kaastra, I., "A comparison of artificial neural network and time series models for forecasting commodity prices", Neurocomputing, 10(2): 169-81, (1996).

[12] Poh, H. L., Yao, J., Jašic, T., "Neural networks for the analysis and forecasting of advertising and promotion impact", Intelligent Systems in Accounting, Finance and Management, 7(4): 253-68, (1998).

[13] Darbellay, G. A., Slama, M., "Forecasting the short-term demand for electricity: Do neural networks stand a better chance?", International Journal of Forecasting, 16(1): 71-83, (2000).

[14] Aminian, F., Suarez, E. D., Aminian, M., Walz, D. T., "Forecasting economic data with neural networks", Computational Economics, 28(1): 71-88, (2006).

[15] Zhuo, W., Li-Min, J., Yong, Q., Yan-Hui, W., "Railway passenger traffic volume prediction based on neural network", Applied Artificial Intelligence, 21(1): 1-10, (2007). 
[16] Yu, L., Wang, S., Lai, K. K., “A neural-network-based nonlinear metamodeling approach to financial time series forecasting", Applied Soft Computing, 9(2): 563-74, (2009).

[17] Kaastra, I., Boyd, M., "Designing a neural network for forecasting financial and economic time series", Neurocomputing, 10(3): 215-36, (1996).

[18] Schierholt, K., Dagli, C. H., "Stock market prediction using different neural network classification architectures", IEEE/IAFE 1996 Conference On Computational Intelligence for Financial Engineering (CIFEr), 72-8, (1996).

[19] Mostafa, M. M., "Forecasting stock exchange movements using neural networks: Empirical evidence from Kuwait”, Expert Systems with Applications, 37(9): 6302-9, (2010).

[20] Naeini, M. P., Taremian, H., Hashemi, H. B., "Stock market value prediction using neural networks", 2010 International Conference On Computer Information Systems and Industrial Management Applications (CISIM), 132-6, (2010).

[21] Devadoss, A. V., Ligori, T. A. A., "Forecasting of stock prices using multi-layer perceptron", International Journal of Computing Algorithm, 2: 440-9, (2013).

[22] Kutlu, B., Ozturan, M., Badur, B., "Stock market prediction using artificial neural networks", Proceedings of the 3rd International Conference on Business, Hawaii, (2003).

[23] Yumlu, S., Gurgen, F. S., Okay, N., "A comparison of global, recurrent and smoothed-piecewise neural models for Istanbul stock exchange (ISE) prediction", Pattern Recognition Letters, 26(13): 2093-103, (2005).

[24] Guresen, E., Kayakutlu, G., Daim, T. U., "Using artificial neural network models in stock market index prediction" Expert Systems with Applications, 38(8): 10389-97, (2011).

[25] Burges, C. J., "A tutorial on support vector machines for pattern recognition", Data Mining and Knowledge Discovery, 2(2): 121-67, (1998).

[26] Mukherjee, S., Osuna, E., Girosi, F., "Nonlinear prediction of chaotic time series using support vector machines", Neural Networks for Signal Processing VII Proceedings of the 1997 IEEE Signal Processing Society Workshop, 511-20, (1997).

[27] Müller, K. R., Smola, A. J., Rätsch, G., Schölkopf, B., Kohlmorgen, J., Vapnik, V., "Predicting time series with support vector machines", International Conference on Artificial Neural Networks, 9991004, (1997).

[28] Smola, A. J., Schölkopf, B., “A tutorial on support vector regression”, Statistics and Computing, 14(3): 199-222, (2004).

[29] Vapnik, V., "Statistical learning Theory”, John Wiley and Sons Inc., (1998).

[30] Cao, L., Tay, F. E., "Financial forecasting using support vector machines", Neural Computing and Applications, 10(2): 184-92, (2001).

[31] Tay, F. E., Cao, L., "Application of support vector machines in financial time series forecasting", Omega, 29(4): 309-17, (2001). 
[32] Tay, F. E., Cao, L., "Improved financial time series forecasting by combining support vector machines with self-organizing feature map”, Intelligent Data Analysis, 5(4): 339-54, (2001).

[33] Tay, F. E., Cao, L., "Modified support vector machines in financial time series forecasting", Neurocomputing, 48(1-4): 847-61, (2002).

[34] Kim, K., "Financial time series forecasting using support vector machines", Neurocomputing, 55(12): 307-19, (2003).

[35] Pai, P. F., Lin, C. S., "A hybrid ARIMA and support vector machines model in stock price forecasting”, Omega, 33(6): 497-505, (2005).

[36] Kumar M., Thenmozhi M., "Forecasting stock index movement: A comparison of support vector machines and random forest", 9th Capital Markets Conference, Indian Institute of Capital Markets Paper, (2006).

[37] Kumar, M., Thenmozhi, M., "Support vector machines approach to predict the S\&P CNX NIFTY index returns", 10th Capital Markets Conference, Indian Institute of Capital Markets Paper, (2007).

[38] Hsu, S. H., Hsieh, J. P. A., Chih, T. C., Hsu, K. C., "A two-stage architecture for stock price forecasting by integrating self-organizing map and support vector regression", Expert Systems with Applications, 36(4): 7947-51, (2009).

[39] Özdemir, A. K., Tolun S., Demirci, "Endeks Getirisi Yönünün İkili Sınıflandırma Yöntemiyle Tahmin Edilmesi: İMKB 100 Endeksi Örneği”, Ömer Halisdemir Üniversitesi İktisadi Ve İdari Bilim Fakültesi Dergisi, 4(2): 45, (2011).

[40] Tayyar, N., Tekin, S., "IMKB-100 endeksinin destek vektör makineleri ile günlük, haftalık ve aylık veriler kullanarak tahmin edilmesi”, Abant İzzet Baysal Üniversitesi Sosyal Bilimler Enstitüsü Dergisi, 13(1): 189-217, (2013).

[41] Yakut, E., Elmas, B., Yavuz, S., "Yapay sinir ağları ve destek vektör makineleri Yöntemleriyle borsa endeksi tahmini”, Süleyman Demirel Üniversitesi İktisadi Ve İdari Bilimler Fakültesi Dergisi, 19(1): 139-57, (2014).

[42] Hochreiter, S., Schmidhuber, J., "Long short-term memory", Neural Computation, 9(8): 1735-80, (1997).

[43] Baccouche, M., Mamalet, F., Wolf, C., Garcia, C., Baskurt, A., "Sequential deep learning for human action recognition", International Workshop on Human Behaviour Understanding, 29-39, (2011).

[44] Fernandez, S., Graves, A., Schmidhuber, J., "An application of recurrent neural networks to discriminative keyword spotting", International Conference on Artificial Neural Networks, 220-9, (2007).

[45] Graves, A., Mohamed, A., Hinton, G., "Speech recognition with deep recurrent neural networks", 2013 IEEE International Conference on Acoustics, Speech and Signal Processing, 6645-9, (2013).

[46] Graves, A., Schmidhuber, J., "Framewise phoneme classification with bidirectional LSTM and other neural network architectures", Neural Networks, 18(5-6): 602-10, (2005).

[47] Graves, A., Schmidhuber, J., "Offline handwriting recognition with multidimensional recurrent 
neural networks", Advances in Neural Information Processing Systems, 545-52, (2009).

[48] Schmidhuber, J., "Deep learning in neural networks: An overview", Neural Networks, 61: 85-117, (2015).

[49] Eck, D., Schmidhuber, J., "Learning the long-term structure of the blues", International Conference on Artificial Neural Networks, 284-9, (2002).

[50] Hochreiter, S., Heusel, M., Obermayer, K., "Fast model-based protein homology detection without alignment", Bioinformatics, 23(14): 1728-36, (2007).

[51] Mayer, H., Gomez, F., Wierstra, D., Nagy, I., Knoll, A., Schmidhuber, J., "A system for robotic heart surgery that learns to tie knots using recurrent neural networks", Advanced Robotics, 22(13-14): 1521-37, (2008).

[52] Schmidhuber, J., Gers, F., Eck, D., "Learning nonregular languages: A comparison of simple recurrent networks and LSTM", Neural Computation, 14(9): 2039-41, (2002).

[53] Giles, C. L., Lawrence, S., Tsoi, A. C., "Noisy time series prediction using recurrent neural networks and grammatical inference", Machine Learning, 44(1-2): 161-83, (2001).

[54] Xiong, R., Nichols, E. P., Shen, Y., "Deep learning stock volatility with google domestic trends" ArXiv Prepr ArXiv151204916, (2015).

[55] Roondiwala, M., Patel, H., Varma, S., "Predicting stock prices using LSTM", International Journal of Science and Research, 6(4): 1754-6, (2015).

[56] Shen, F., Chao, J., Zhao, J., "Forecasting exchange rate using deep belief networks and conjugate gradient method", Neurocomputing, 167: 243-53, (2015).

[57] Pang, X. W., Zhou, Y., Wang, P., Lin W., Chang, V., "Stock market prediction based on deep long short term memory neural network", Complexis, 102-8, (2018).

[58] Fischer, T., Krauss, C., "Deep learning with long short-term memory networks for financial market predictions", European Journal of Operational Research, 270(2): 654-69, (2018).

[59] Kohonen, T., “An introduction to neural computing”, Neural Networks, 1(1): 3-16, (1988).

[60] Lippmann, R. P., “An introduction to computing with neural nets", Artificial Neural Networks: Theoretical Concepts, 36-54, (1988).

[61] Rumelhart, D. E., McClelland, J. L., Group, P. R., "Parallel distributed processing: Exploration in the microstructure of cognition, Vol. 1", (1986).

[62] Cortes, C., Vapnik, V., "Support-vector networks”, Machine Learning, 20(3): 273-97, (1995).

[63] Vapnik, V., Golowich, S. E., Smola, A. J., "Support vector method for function approximation, regression estimation and signal processing", Advances in Neural Information Processing Systems, 281-7, (1997). 